\title{
Impacts of Tick Size Reduction on Transaction Costs
}

\author{
$\mathrm{Yu} \mathrm{Wu}$ \\ Southwestern University of Finance and Economics \\ Research Institute of Economics and Management \\ 55 Guanghuacun Street, Chengdu, Sichuan, China 610074
}

Tel: 86-288-735-2921 E-mail: yorkwood2000@yahoo.com

Tim Krehbiel

Department of Finance, Oklahoma State University

332 Spears School of Business, Stillwater, OK 74078

Tel: 405-744-8660Ｅ-mail: tim.krehbiel@okstate.edu

\author{
B. Wade Brorsen (Corresponding Author) \\ Department of Agricultural Economics, Oklahoma State University \\ 414 Agricultural Hall, Stillwater, OK 74078-6026 \\ Tel: (405)-744-6836 E-mail: wade.brorsen@okstate.edu
}

Received: June 8, 2011

Accepted: July 22, 2011

Published: November 1, 2011

doi:10.5539/ijef.v3n6p57

URL: http://dx.doi.org/10.5539/ ijef.v3n6p57

\begin{abstract}
This study investigates the impact of changes in tick size on transaction costs of different size trades. We use samples drawn from shares with extreme high/low price and high/low trading volume to examine the impact of the 1997 and 2001 reductions in tick size on the New York Stock Exchange. For high-price low-volume NYSE shares, the 1997 change from pricing in $\$ 1 / 8$ s to pricing in $\$ 1 / 16$ ths clearly increased effective spreads for transactions of even the smallest size, but the effect of the further reductions in 2001 while still mostly positive for high-price low-volume stocks was not statistically significant. Thus, while tick size reduction does reduce liquidity costs for most stocks, it does not do so for all stocks.
\end{abstract}

Keywords: Bid-ask spread, Execution cost, Liquidity, Microstructure, Stock price

\section{JEL classification codes: D40, G12}

\section{Introduction}

In 1997, U. S. Congress passed the Common Cents Stock Pricing Act to convert tick size, the smallest increment in which stock prices can move, from fractions to decimals. On June 24, 1997, the New York Stock Exchange (NYSE), one of seven domestic stock exchanges, reduced the minimum tick size from $\$ 1 / 8$ to $\$ 1 / 16$, and on January 29,2001 , further reduced it from $\$ 1 / 16$ to $\$ 0.01$. The reductions in minimum tick size on both domestic and international exchanges have sparked a considerable volume of academic literature that examines the relationship between minimum tick size and market liquidity. Given the breadth of this research, a striking divergence remains in opinions regarding the ultimate impact on market liquidity of these reductions in minimum price variation.

Prior empirical research has reached a general agreement that tick size reduction uniformly reduces transaction costs for small transactions. However, the impact on transaction costs of traders submitting orders of size greater than quoted depth is less certain. Jones and Lipson (2001) and Goldstein and Kavajecz (2000) demonstrate that a reduction in minimum tick size can adversely impact transaction costs for large transactions on the NYSE. Our study adds to the growing literature in this area by determining how the impacts of changes in tick size on market liquidity vary with trade size, stock price, and market volume. Past literature studying these two events at NYSE has studied many of these effects individually, but not all combinations of these effects. We find that the 1997 and 2001 tick size reductions induced a pattern of changes in spreads, market depth, and effective spreads for transactions sorted by relative tick size, trading volume, and trade size consistent with the existence of an optimal tick size 
schedule as hypothesized by Seppi (1997). Our study, using samples of NYSE stocks with extremely low/high price (large/small relative ticks) and low/high trading volume, finds results similar to those of Aitken and Comerton-Forde (2005) regarding the 1995 tick size reduction on the Australian Stock Exchange. Our results indicate that transaction costs for orders of small size increase for the group of stocks with both small relative tick size and small trading volume. The remainder of our paper is organized as follows: section II provides a review of existing literature relevant to this study; section III describes the sample selection criteria and sample descriptive statistics; section IV discusses the testing methodology; section $\mathrm{V}$ presents an analysis of changes in effective spreads surrounding the 1997 and 2001 NYSE tick size reductions, and section VI presents our conclusions.

\section{Tick size reduction and market liquidity}

From its beginning with the Buttonwood Agreement in 1792 until the first reduction in minimum tick size in 1997, minimum price variation for the majority of NYSE stocks has been $\$ 1 / 8$ (Note 1). Liquidity, defined as the ability to transact at a price near the current value, is provided on the NYSE by three groups of market participants; limit order traders, floor brokers, and specialists. Traders who place orders in the limit order book provide liquidity by publicly stating the amount they are willing to trade at a certain price. Floor brokers provide liquidity by filling orders that may or may not be displayed to the general market. Specialists may supply additional liquidity by choosing to offer a lower spread or provide more depth than is provided by the limit order book and/or floor brokers. Specialists operating within rules established by an exchange, match buy and sell orders at the best available prices. On the NYSE, specialists fill orders according to both time and price precedence, but are also allowed to give precedence to large orders.

Minimum tick size determines the minimum price to acquire order precedence through price priority when time precedence is enforced. It also determines the minimum transaction cost for entering and exiting a position. If minimum tick sizes are too small, limit orders and specialists' quotes offer market participants an opportunity nearly equivalent to front running by placing a limit order on the same side of the market, but offering a slightly better quote. A market participant with knowledge of the limit orders would then have a nearly free option to reverse the position at the pre-existing limit price or quote should the share price move against the position. An economically significant minimum tick size is a deterrent to this practice of quote (near) matching. Large minimum tick size forces quote matchers to improve price significantly if they wish to cut in front of pre-existing quotes (Harris 1994). Too small a minimum tick size encourages quote matching and discourages market participants from providing liquidity (quotes/limit orders for substantial size) throughout the breadth of the limit order book.

A market's bid ask spread represents a transaction cost for traders entering and exiting a position. The minimum tick size, thus defines the minimum transaction cost. Models explaining the economic determinants of optimal bid ask spread generally build from costs incurred by liquidity providers. These cost components have been identified as order processing, inventory holding, and adverse selection. Adverse selection refers to losses from transacting with a better informed counterparty. Most models of this type suggest that specialists and other liquidity providers implicitly maintain an upward sloping schedule of bid and ask quotations for which optimal spreads increase with order size. Liquidity providers optimal spread for a given size transaction is a latent spread since it is not observed when tick sizes are larger than the optimal spread.

Trading volume is recognized as an important determinant of the adverse selection component of the bid ask spread. The divergence between the last transaction price and the current value should be smaller in markets with more frequent trading. Hence, the greater the trading volume, the smaller the adverse selection cost component will be. For low priced frequently traded shares, the observed bid ask spread may be constrained above latent spreads due to the minimum tick size rule. In this circumstance, suppliers of liquidity receive artificially inflated profits; especially for trades of small size where adverse selection costs are less likely. In a market with a binding minimum tick size, profit maximizing liquidity providers will offer greater quoted depths than they would in the absence of such a rule. For infrequently traded stocks, a minimum tick size is less likely to artificially constrain bid ask spreads above liquidity providers' latent spreads. For these markets, latent spreads are larger due to the costs associated with a greater likelihood of adverse selection. Relative to markets where minimum tick size is a binding constraint, liquidity providers are expected to supply less market depth than when minimum tick size is not a binding constraint.

Chordia and Subrahmanyam (1995), Bernhardt and Hughson (1996), Kandel and Marx (1997), and Anshuman and Kalay (1998) argue that decreasing tick size reduces the wedge between the minimum possible spread and liquidity suppliers' latent spreads and thus reduces transaction costs. Harris (1994) argues that although transaction costs of small size trades decrease due to tick size reduction, the impact on transaction costs of large size trades is ambiguous. Liquidity suppliers may increase quoted spreads for large size orders to recapture the lost profit due to reducing 
spreads for small size orders, reduce their quoted depth at a given price, move quoted depth to limit prices further from the best available quotes, or leave the market entirely.

Cordella and Foucault (1999) also conclude that reducing tick size may not improve market liquidity. Harris (1997, 1999, 2003) argues that small tick size would reduce the revenues of liquidity providers, could weaken the incentive to provide liquidity, and could potentially damage market quality. Glosten (1995) predicts that reducing tick size will decrease the transaction costs of small size trades, but forecasts that a reduction in tick size will have no effect on large size trades. Angel (1997) proposes an optimal relative tick size, which represents a trade-off between the profits of market makers and the transaction costs of common traders.

Seppi (1997) develops a microstructure model of market liquidity. In Seppi's model, which incorporates institutional features like those of the NYSE, mandating a single minimum tick size for all transactions is not optimal. Instead optimal tick size is a function of trade size with institutional orders for large blocks having a larger optimal tick size and small retail transactions having a smaller optimal tick size.

Prior empirical research most often finds that tick size reduction reduces bid ask spreads and quoted depth. Beyond these descriptive empirical findings, little agreement exists across studies concerning the impact of tick size reduction on aggregate transaction costs. On September $3^{\text {rd }}, 1992$, the American Stock Exchange (AMEX) reduced tick size from $1 / 8$ to $1 / 16^{\text {th }}$ for shares with a price between $\$ 1$ and $\$ 5$. Using this sample, Ahn, Cao, and Choe (1996) test Harris's (1994) model for tick size reduction and find that bid-ask spreads decline after tick size reduction. In contrast to the findings of our study, the authors find the AMEX tick size reduction does not have much impact on infrequently traded stocks.

Most empirical studies of tick size reduction find that reducing tick size both reduces posted bid ask spreads and reduces quoted market depth. Not surprisingly, conclusions reached concerning the net impact on liquidity are mixed. Van Ness et al. (2000) survey 12 studies and illustrate the disparate conclusions presented in the literature. Their empirical results indicate a significant reduction in spreads at NYSE, AMEX, and NASDAQ following tick size reduction. Chakravarty et al. (2004) find that decimalization leads to significantly lower quoted and effective bid-ask spreads. Bessembinder (2003) examines trade execution costs and market quality after decimalization and finds that quoted bid-ask spreads declined, and the percentage of shares receiving price improvements increased.

In studies considering the impact of tick size reduction on transaction costs for large size orders, Goldstein and Kavajecz (2000) use limit order data provided by the NYSE to analyze the impact of the 1997 tick size reduction on quoted depth and the dispersion of depth in the limit order book. They find narrower spreads but less cumulative depth in the limit order book after the change. They conclude that due to the reduced tick size, traders submitting small orders are better off while traders transacting in large size orders suffer higher transaction costs. Jones and Lipson (2001) investigate institutional trade records and find that after NYSE and NASDAQ reduced tick size from $\$ 1 / 8$ to $\$ 1 / 16$, institutional transaction costs increased, especially for sizes of at least 10,000 shares.

These studies illustrate that the effect of tick size reduction is sensitive to both trade size and trading volume with reductions in quoted spread and depth being the greatest for the most frequently traded stocks. For stocks that are infrequently traded, Goldstein and Kavajecz (2000) find that the average quoted spread actually increases. The adverse consequence of tick size reduction for infrequently traded stocks is also documented in a study examining tick size reduction on the Australian Stock Exchange by Aitken and Comerton-Forde (2005) who find that stocks with small relative tick size and low trading volume experience reduced liquidity after the tick size reduction.

\section{Data and Descriptive Statistics}

The studies by Harris (1994), Goldstein and Kavajecz (2000), and Aitken and Comerton-Forde (2005), imply that changes in transaction costs induced by tick size reduction are a function of price level, trading volume, and transaction size. To examine the influence of price and volume on the change in transaction costs induced by reducing tick size, we collect extreme price and volume samples for the NYSE's 1997 and 2001 tick size reductions. Within price/volume groups, transactions are parsed into 10 trade size groupings.

Van Ness, et al. (2000) evaluate the 1997 tick size reduction using samples from NYSE, AMEX and NASDAQ traded shares and the following selection criteria:

1. AMEX stocks with at least 10 trades per day and NASDAQ and NYSE stocks with at least 40 trades per day

2. Stocks with an average price of at least $\$ 10$

Van Ness, et al. (2000) only classify stocks by price and do not consider volume or trade size. Our interest is to determine if the tick size reduction has the greatest impact on large trades in stocks with extremely low/high price and low/high volume. 
Extreme low/high price and low/high trading volume shares are identified using the Center for Research in Security Prices (CRSP) data set. High-price low volume (HPLV) samples and high price high volume (HPHV) samples consist of all NYSE listed firms with a three month minimum share price greater than $\$ 60$ (1997) or $\$ 80$ (2001) for the three months preceding the tick size reduction. For the low volume group, average monthly trading volume is less than 1,000,000 shares (HPLV) and for the high volume group average monthly trading volume is greater than $10,000,000$ shares (HPHV). Low price samples consist of all NYSE listed firms with three month maximum share price less than $\$ 10$ but greater than $\$ 1$ for the three months preceding the tick size reduction. Low price low volume (LPLV) stocks have average monthly trading volume less than 200,000 shares, while low price high volume (LPHV) stocks have average monthly trading volume greater than 4,500,000. The pre-event period for the 1997 tick size reduction spans March 23, 1997 through June 23, 1997, and the post-event period June 24, 1997 through October 6, 1997. The pre-event period for the 2001 tick size reduction spans October 26, 2000 through January 26, 2001, and the post-event period January 29, 2001 through April 30, 2001. Because the 2001 tick size reduction was implemented in stages, firms converted to decimal trading prior to January 29 are eliminated from extreme price and volume samples (Note 2).

The NYSE's Trade and Quote's (TAQ) trade records are used to collect intraday bid and ask quotes, transaction prices and trade sizes. We separate transactions into 10 size groups based on the number of shares traded.

Chakravarty, et al. (2004), in an examination of the impact of the NYSE's 2001 move to decimal pricing, merge data from the Consolidated Tape Association and the Consolidated Quotation System to evaluate market measures associated with liquidity for five trade size categories. To construct matched samples during the phase-in period, their sample consists of 79 firms affected by the phased pilot program. Given our focus contrasting high and low trade volume samples, we use a finer grid for larger trades and separate transactions by size into 10 groups (Note 3).

For our subsamples, pre-event average quoted spread, spread as a percentage of the bid ask midpoint, and quoted depths are provided in Table 2. Contrasting these descriptive statistics for our subsamples with those found in previous studies is informative. Sorting NYSE firms by pre-event dollar spread, Jones and Lipson (2001), who examine the 1997 event, report an average dollar spread for the quartile of firms with the largest spread of $\$ 0.238$. In most cases, our sample selection criteria clearly results in shares that trade in markets with significantly larger bid ask spreads. The extreme low price samples of our study also exhibit significantly larger percentage spreads than Van Ness, et al. (2000) who only considered quartiles.

Harris (1994, 1997, and 1999) argues that the net impact of tick size reduction may be to diminish market quality because liquidity suppliers have less incentive to supply liquidity to the market. The ambiguous impact of tick size reduction on market quality is clearly illustrated from examining the ratio of post- to pre-change quoted spreads and depth (Table 3). For extreme low-price stocks, the 1997 reduction from 1/8 to $1 / 16$ significantly reduces dollar bid ask spread by a minimum of $10 \%$, however quoted depth also suffers a reduction of at least $44 \%$. As noted by Lipson and Jones (2001) and others, the reduction in quoted depth at best available bid and ask prices (inside quotes) by itself is not surprising. Post-event redistribution of market depth across a finer price grid is likely to reduce quoted depth at any single price. For our study's high volume stocks, quoted depth is reduced significantly by both the 1997 and 2001 tick size reductions. However, quoted spreads decrease significantly only for low price stocks, for which tick size is presumably large relative to latent spreads. The impact on quoted spreads of high-price and high-volume stocks is mixed for the 1997 and 2001 events.

Notice that for the 1997 change, the indicated change in market liquidity for the high-price low-volume sample is unambiguous. Dollar bid ask spreads are $8 \%$ greater after tick size reduction, and quoted depth is also significantly smaller in the post-event period. The market liquidity of HPLV stocks is adversely impacted by the NYSE's 1997 tick size reduction.

For small orders, the quoted bid ask spread is a good indicator of the execution cost of a trade. For large orders, bid ask spread may not fully represent the cost. The effective spread better captures the cost of a round-trip order by including both price improvement, liquidity supplier's offers to execute an order at a price better than quoted, and market impact, (realized spread greater than quoted spread due to the order size). Effective spread is defined as twice the difference between the trade execution price and the mid-point of the bid ask quote at the time of the transaction.

\section{Methodology}

A paired differences test is used to determine if the average effective spreads for transactions of a given size differ in the pre- and post-event periods. For the $j^{\text {th }}$ stock in the $k^{\text {th }}$ transaction size group, the $i^{\text {th }}$ transaction's dollar effective spread is 
$D E S_{k, j, i}=2\left|P_{k, j, i}-M_{k, j, i}\right|$.

$P_{k, j, i}$ is the price of the $i^{\text {th }}$ transaction for the $j^{\text {th }}$ stock in the $k^{\text {th }}$ size group, and $M_{k, j, i}$ is the midpoint of the quoted spread at the time of the $i^{\text {th }}$ transaction. The corresponding percentage effective spread is:

$P E S_{k, j, i}=2\left|P_{k, j, i}-M_{k, j, i}\right| / M_{k, j, i}$.

The average dollar effective spread for the $j^{\text {th }}$ stock, in the $k^{\text {th }}$ group, in the pre-event period is

$$
A D E S_{k, j}^{\text {pre }}=\frac{1}{n_{k, j}^{\text {pre }}} \sum_{i=1}^{n} D E S_{k, j, i}^{\text {pre }},
$$

where $n_{k, j}^{\text {pre }}$ is the total number of transactions in the $k^{\text {th }}$ size group for the $j^{\text {th }}$ stock, , in the pre-event period. The corresponding average percentage effective spread is defined similarly. Following the same process, we obtain the average dollar and percentage effective spread in the $k^{\text {th }}$ size group, for the $j^{\text {th }}$ stock, in the post-event period.

We use paired differences tests to test the null hypothesis that average effective spreads for each group are the same in pre- and post-event periods. The differences are between the average post-event effective spread and the average pre-event effective spread for each stock in each size group, $D_{k, j}=A D E S_{k, j}^{p o s t}-A D E S_{k, j}^{p r e}$. TAQ data for the firms of the extreme price and volume samples do not contain transactions for all stocks for all ten trade size categories in both pre-event and post-event periods. Stocks in the $k^{\text {th }}$ group that do not have transactions in both pre- and postevent periods are deleted.

\section{Change in average transaction cost due to reduction in tick size}

The changes in average effective spreads for markets with low trading volume are discussed first. For HPLV stocks (Panel A of Table 4), tick size reduction increased transaction costs as measured by effective spreads for all size transactions. The 1997 tick size reduction significantly increases transaction costs by at least $\$ 0.05$ for transactions of 4,900 shares or less. For transactions involving fewer than 4,900 shares of HPLV stocks, the tick size reduction from $\$ 1 / 8$ to $\$ 1 / 16$ apparently reduced the relative minimum tick size below the optimal level. Given the small relative tick size in these markets, the minimum tick size is unlikely a binding constraint prior to the event. The effect of the 2001 decimalization on HPLV stocks' transaction costs was not statistically significant although a further increase did occur in most size categories.

In general for LPLV (Panel B of Table 4) markets, the NYSE's tick size reductions produce smaller transaction costs as measured by effective spread. Relative to markets for high priced stocks, minimum tick size is more likely a binding constraint for stocks in low-price, low-volume markets. For LPLV stocks, tick size reductions in 1997 and 2001 reduce the wedge between market quotes and liquidity provider's latent quotes, thereby reducing transaction costs for stocks with low-price and low trading volume.

As discussed previously, the liquidity providers' latent spreads in markets with frequently traded stocks will be smaller than in markets with low trading volume. Changes in effective spread for HPHV stocks, presented in Table 5, produce little evidence of significant effects on trading costs. In contrast, tick size reductions produce significant reductions in transaction costs for LPHV stocks (Table 6). For LPHV stocks, each tick size reduction reduces average transaction costs by approximately $\$ 0.04$ for all transaction size groups considered. The difference in these results is potentially explained by the fact that the relative minimum tick in the low priced stock groups was very large relative to the liquidity provider's latent spreads prior to tick size reduction, and the change allowed liquidity providers to narrow effective spreads.

\section{Conclusions}

Similar to Goldstein and Kavajecz (2000), we find that trading volume influences the impact of tick size reduction on transaction costs. Infrequently traded stocks are more likely to show increased transaction costs after a tick size reduction. Trading volume provides a proxy for the size of latent spreads. For high volume markets with correspondingly small latent spreads, reducing tick sizes is expected to reduce transaction costs. For example if liquidity suppliers' latent spreads for a given size transaction are smaller than half of one pre-event tick, the pre-event spread would be one pre-event tick. After a tick size reduction from $\$ 1 / 8$ to $\$ 1 / 16$, the empirical spread will be one post-event tick, since the reduced tick size is still greater than the liquidity suppliers' latent spread. However, when volume is low and liquidity suppliers' latent spread for a given size order is greater than half but smaller than one pre-event tick, the discreteness causes the post-event tick to be smaller than the liquidity suppliers' 
latent spread. In this example and cutting the tick size in half, the post-event spread will be either two or three post-event ticks and thus there would either be no change in effective spread or effective spreads increase after tick size reduction. The change in the average effective spread for high-price low-volume stocks shows that tick size reduction can indeed increase transaction costs.

Chordia and Subrahmanyam (1995), Bernhardt and Hughson (1996), Kandel and Marx (1997), and Anshuman and Kalay (1998) argue that decreasing tick size reduces the wedge between posted prices and liquidity providers' reservation prices. Decimalization allows a very small wedge. After decimalization, the difference between empirical spreads and liquidity providers' reservation spreads is less than one cent. Before decimalization, empirical spreads were greater than liquidity providers' reservation spreads by at most $\$ 0.0625$. On average, decimalization should reduce percentage transaction costs by more than the tick size reduction from $\$ 1 / 8$ to $\$ 1 / 16$. This implication is supported by the reduction in average percentage effective spread for low price stocks. The average percentage effective spread decreases by a greater absolute amount for the 2001 decimalization than for the 1997 tick size reduction.

\section{References}

Ahn, H., Cao, C.Q. \& Choe, H. (1996). Tick Size, Spread, and Volume. Journal of Financial Intermediation. 5, 2-22, http://dx.doi.org/10.1006/jfin.1996.0002 .

Aitken, M. \& Comerton-Forde, C. (2005). Do Reductions in Tick Sizes Influence Liquidity? Accounting and Finance. 45, 171-184, http://dx.doi.org/10.1111/j.1467-629x.2004.00128.x .

Angel, J. J. (1997). Tick Size, Share Prices, and Stock Splits. Journal of Finance. 52, 655-681, http://dx.doi.org/10.2307/2329494

Anshuman, V. R. \& Kalay, A. (1998). Market-Making with Discrete Prices. Review of Financial Studies. 11, 81-109, http://dx.doi.org/10.1093/rfs/11.1.81

Bernhardt, D. \& Hughson, E. (1996). Discrete Pricing and the Design of Dealerships Markets. Journal of Economic Theory. 71, 148-182, http://dx.doi.org/10.1006/jeth.1996.0113

Bessembinder, H. (2003). Trade Execution Costs and Market Quality after Decimalization. Journal of Financial and Quantitative Analysis. 38 (4), 747-777, http://dx.doi.org/10.2307/4126742

Chakravarty, S., R. A. Wood \& R. A. Van Ness. (2004). Decimals and Liquidity: A Study of NYSE. The Journal of Financial Research. 152 (1), 75-94, http://dx.doi.org/10.1111/j.1475-6803.2004.00078.x

Chakravarty, S., Panchapagesan, V. \& Wood, R.A. (2005). Did Decimalization Hurt Institutional Investors? The Journal of Financial Market. 8 (2005) 400-420, http://dx.doi.org/10.1016/j.finmar.2005.05.002

Chordia, T. \& Subrahmanyam, A. (1995). Market-Making, the Tick Size and Payment for the Order Flow. Journal of Business. 68, 543-575, http://dx.doi.org/10.1086/296676

Cordella, T. \& Foucault, T. (1999). Minimum Price Variations, Time Priority, and Quote Dynamics. Journal of Financial Intermediation. 8, 141-173, http://dx.doi.org/10.1006/jfin.1999.0266

Glosten, L. (1995). Competition and the set of allowable prices. Unpublished working paper. Columbia University, New York.

Goldstein, M. A. \& Kavajecz, K.A. (2000). Eighths, Sixteenths, and Market Depth: Changes in Tick Size and Liquidity Provision on NYSE. Journal of Financial Economics. 56, 125-149, http://dx.doi.org/10.1016/S0304-405X(99)00061-6

Harris, L. E. (1994). Minimum Price Variations, Discrete Bid-Ask Spreads, and Quotation Sizes. The Review of Financial Studies. 7 (1), 149-178, , http://dx.doi.org/10.1093/rfs/7.1.149

Harris, L. E. (1997). Decimalization: A review of the arguments and evidence. Working Paper, Univ. of Southern California. Available at http://www-bcf.usc.edu/ /harris/ACROBAT/decimal.pdf.

Harris, L. E. (1999). Trading in pennies: A survey of the issues. Working Paper, Univ. of Southern California. Available at http://www-bcf.usc.edu/ lharris/ACROBAT/pennies.pdf.

Harris, L. (2003). Trading and exchanges: Market microstructure for practitioners. Oxford: Oxford University Press.

Jones, C. M. \& Lipson, M.L. (2001). Sixteenths: Direct Evidence on Institutional Execution Costs. Journal of Financial Economics. 59, 253-278, http://dx.doi.org/10.1016/S0304-405X(00)00087-8

Kandel, E. \& Marx, L. (1997). NASDAQ Market Structure and Spread Patterns. Journal of Financial Economics. 


\section{5, 61-89, http://dx.doi.org/10.1016/S0304-405X(96)00894-X}

Seppi, D. J. (1997). Liquidity Provision with Limit Orders and a Strategic Specialist. The Review of Financial Studies. 10 (1), 103-150, http://dx.doi.org/10.1093/rfs/10.1.103

Van Ness, B. F., Van Ness, R.A. \& Pruitt, S.W. (2000). The Impact of the Reduction in Tick Increments in Major U.S. Markets on Spreads, Depth, and Volatility. Review of Quantitative Finance and Accounting. 15: 153-167, http://dx.doi.org/10.1023/A:1008369114062

Notes

Note 1. NYSE Rule 62 required minimum tick size of $\$ 1 / 8$ for shares with a price greater than $\$ 1, \$ 1 / 16$ for stocks with a price less than $\$ 1$ but greater than $\$ 0.25$, and $1 / 32$ for shares priced less than $\$ 0.25$.

Note 2. The 2001 tick size reduction for $\$ 1 / 16$ to $\$ 0.01$ was accomplished in stages. The NYSE reduced tick size to $\$ 0.01$ for seven securities on August 28, 200; for 57 additional securities on September 25, 2000; and for an additional 94 securities on December 5, 2000. All remaining stocks began trading in decimals on January 29, 2001.

Note 3. The ten transaction size groups are: 100 to 400 shares, 500 to 900 shares, 1,000 to 4,900 shares, 5,000 to 9,900 shares, 10,000 to 49,900 shares, 50,000 to 74,900 shares, 75,000 to 99,900 shares, 100,000 to 249,900 shares, 250,000 to 499,900 shares, and greater than 499,900 shares.

Table 1. Sub samples for investigation of the 1997 and 2001 NYSE tick size reductions.

\begin{tabular}{lll}
\hline Category & 1997 & 2001 \\
\hline HPLV: $S>\$ 60, V<1 M M$ & 27 & 20 \\
HPHV: $\mathrm{S}>\$ 80, \mathrm{~V}>10 \mathrm{MM}$ & 25 & 23 \\
LPLV: $\mathrm{S}<$ \$10,V $<200 \mathrm{M}$ & 33 & 50 \\
LPHV: $\mathbf{S}<\mathbf{\$ 1 0 , V}>\mathbf{4 . 5 M M}$ & 34 & 42 \\
\hline
\end{tabular}

Note: High-price samples; HPLV, HPHV contain all NYSE listed firms with a three month minimum share price greater than $\$ 60$ (1997) or $\$ 80$ (2001) for the three months preceding the tick size reduction and average monthly trading volume less than 1,000,000 shares (HPLV); or average monthly trading volume greater than 10,000,000 shares (HPHV). Low-price samples contain all NYSE listed firms with three month maximum share price less than $\$ 10$ but greater than $\$ 1$ for the three months preceding the tick size reduction and average monthly trading volume less than 200,000 shares (LPLV); average monthly trading volume greater than 4,500,000 shares (LPHV).

Table 2. Pre-event period average dollar spread, percentage spread and depths 3/23/1997 - 6/23/1997 and $10 / 26 / 2000-1 / 26 / 2001$.

\begin{tabular}{lllll}
\hline \multicolumn{1}{c}{ Category } & \$-Spread & \%-Spread & Bid & Ask \\
\hline 1997 & & & & \\
HPLV & 0.976 & $0.74 \%$ & 412 & 518 \\
HPHV & 0.390 & $0.40 \%$ & 1762 & 2018 \\
LPLV & 0.356 & $5.51 \%$ & 2751 & 2434 \\
LPHV & 0.212 & $3.68 \%$ & 23778 & 23946 \\
2001 & & & & \\
HPLV & 1.358 & $1.03 \%$ & 260 & 281 \\
HPHV & 0.576 & $0.61 \%$ & 846 & 1121 \\
LPLV & 0.434 & $6.37 \%$ & 948 & 792 \\
LPHV & 0.204 & $4.31 \%$ & 17736 & 16683 \\
\hline
\end{tabular}


Table 3. Percentage change in quoted bid ask spreads, percentage spreads and depth at the inside quotes NYSE 1997 tick size reduction from $1 / 8$ to $1 / 16$ and 2001 NYSE tick size reduction from $1 / 16$ to 0.01 .

\begin{tabular}{lllll}
\hline Category & $\$$-Spread & $\%$-Spread & Bid & Ask \\
\hline 1997 & & & & $-14.67 \%^{\mathbf{b}}$ \\
HPLV & $8.15 \%^{\mathbf{a}}$ & $1.34 \%$ & $-12.14 \%^{\mathbf{a}}$ & $-42.42 \%^{\mathbf{a}}$ \\
HPHV & $3.54 \%$ & $-7.32 \%^{\mathbf{b}}$ & $-42.57 \%^{\mathbf{a}}$ & $-46.75 \%^{\mathbf{b}}$ \\
LPLV & $-10.52 \%^{\mathbf{a}}$ & $-21.89 \%^{\mathbf{a}}$ & $-44.75 \%$ & $-45.57 \%^{\mathbf{a}}$ \\
LPHV & $-15.21 \%^{\mathbf{a}}$ & $-23.64 \%^{\mathbf{a}}$ & $-48.96 \%^{\mathbf{a}}$ & \\
2001 & & & & $-6.05 \%$ \\
HPLV & $-14.41 \%$ & $2.53 \%$ & $-5.77 \%$ & $-32.29 \%^{\mathbf{b}}$ \\
HPHV & $9.62 \%$ & $22.31 \%^{\mathbf{b}}$ & $-33.57 \%^{\mathbf{a}}$ & $4.92 \%^{\mathbf{a}}$ \\
LPLV & $-37.1 \%^{\mathbf{a}}$ & $-42.89 \%^{\mathbf{a}}$ & $-4.54 \%$ & $-77.11 \%^{\mathbf{a}}$ \\
LPHV & $-15.89 \%^{\mathbf{a}}$ & $-24.47 \%^{\mathbf{a}}$ & $-81.76 \%^{\mathbf{b}}$ & \\
\hline
\end{tabular}

${ }^{a}$ statistically different from zero at the $1 \%$ confidence level

${ }^{\mathrm{b}}$ statistically different from zero at the $5 \%$ confidence level

Table 4. Change in dollar and percentage effective spread Panel A: High-price \& Low-volume stocks 1997 and 2001 NYSE tick size reductions; Panel B: Low-price and Low-volume stocks 1997 and 2001 NYSE tick size reductions.

\begin{tabular}{|c|c|c|c|c|c|c|c|c|}
\hline \multirow[b]{2}{*}{ Size } & \multicolumn{4}{|l|}{1997} & \multicolumn{4}{|l|}{2001} \\
\hline & Sample & Pre & Post & Change & Sample & Pre & Post & Change \\
\hline Panel A: & \multicolumn{8}{|c|}{ Dollar effective spread High-price and Low-volume } \\
\hline 1 & 27 & 0.310 & 0.359 & $0.049^{\mathrm{a}}$ & 20 & 0.550 & 0.625 & 0.076 \\
\hline 2 & 27 & 0.289 & 0.355 & $0.066^{\mathrm{a}}$ & 20 & 0.527 & 0.711 & 0.184 \\
\hline 3 & 27 & 0.291 & 0.346 & $0.055^{\mathrm{a}}$ & 20 & 0.581 & 0.642 & 0.061 \\
\hline 4 & 19 & 0.277 & 0.343 & 0.067 & 17 & 0.768 & 0.693 & -0.076 \\
\hline \multirow[t]{2}{*}{5} & 16 & 0.258 & 0.331 & 0.073 & 13 & 0.627 & 0.726 & 0.099 \\
\hline & \multicolumn{8}{|c|}{ Percentage effective spread High-price and Low-volume } \\
\hline 1 & 27 & $0.28 \%$ & $0.30 \%$ & $0.02 \%{ }^{\mathbf{b}}$ & 20 & $0.42 \%$ & $0.53 \%$ & $0.11 \%$ \\
\hline 2 & 27 & $0.32 \%$ & $0.35 \%$ & $0.03 \%{ }^{\mathbf{b}}$ & 20 & $0.50 \%$ & $0.73 \%$ & $0.23 \%$ \\
\hline 3 & 27 & $0.32 \%$ & $0.36 \%$ & $0.03 \%{ }^{\mathbf{b}}$ & 20 & $0.57 \%$ & $0.68 \%$ & $0.11 \%$ \\
\hline 4 & 19 & $0.35 \%$ & $0.38 \%$ & 0.028 & 17 & $0.73 \%$ & $0.78 \%$ & $0.05 \%$ \\
\hline 5 & 16 & $0.34 \%$ & $0.39 \%$ & 0.051 & 13 & $0.69 \%$ & $0.75 \%$ & $0.07 \%$ \\
\hline Panel B: & \multicolumn{8}{|c|}{ Dollar effective spread Low-price and Low-volume } \\
\hline 1 & 33 & 0.131 & 0.107 & $-0.024^{\mathrm{a}}$ & 50 & 0.291 & 0.095 & $-0.196^{\mathrm{a}}$ \\
\hline 2 & 33 & 0.131 & 0.126 & -0.005 & 49 & 0.243 & 0.114 & $-0.129^{\mathrm{a}}$ \\
\hline 3 & 33 & 0.138 & 0.126 & -0.012 & 50 & 0.252 & 0.118 & $-0.134^{\mathrm{a}}$ \\
\hline 4 & 30 & 0.154 & 0.130 & $-0.024^{b}$ & 40 & 0.290 & 0.147 & $-0.143^{\mathrm{a}}$ \\
\hline \multirow[t]{2}{*}{5} & 20 & 0.144 & 0.141 & -0.002 & 24 & 0.260 & 0.115 & $-0.145^{\mathrm{a}}$ \\
\hline & \multicolumn{8}{|c|}{ Percentage effective spread Low-price and Low-volume } \\
\hline 1 & 33 & $2.05 \%$ & $1.51 \%$ & $-0.55 \%{ }^{\mathrm{a}}$ & 50 & $4.40 \%$ & $1.50 \%$ & $-2.90 \%{ }^{\mathrm{a}}$ \\
\hline 2 & 33 & $2.06 \%$ & $1.68 \%$ & $-0.37 \%{ }^{\mathbf{b}}$ & 49 & $4.16 \%$ & $1.91 \%$ & $-2.26 \% \mathrm{a}$ \\
\hline 3 & 33 & $2.49 \%$ & $1.93 \%$ & $-0.56 \%{ }^{\mathrm{a}}$ & 50 & $4.62 \%$ & $2.14 \%$ & $-2.48 \%{ }^{\mathrm{a}}$ \\
\hline 4 & 30 & $2.99 \%$ & $2.32 \%$ & $-0.67 \%{ }^{\mathbf{b}}$ & 40 & $5.24 \%$ & $2.36 \%$ & $-2.88 \%{ }^{\mathrm{a}}$ \\
\hline 5 & 20 & $2.82 \%$ & $2.52 \%$ & $-0.29 \%$ & 24 & $4.52 \%$ & $2.13 \%$ & $-2.38 \%^{\mathrm{a}}$ \\
\hline
\end{tabular}


Table 5. Change in dollar and percentage effective spread High-price \& High-volume stocks 1997 and 2001 NYSE tick size reductions.

\begin{tabular}{|c|c|c|c|c|c|c|c|c|}
\hline \multirow[b]{2}{*}{ Size } & \multicolumn{4}{|l|}{1997} & \multicolumn{4}{|l|}{2001} \\
\hline & Sample & Pre & Post & Change & Sample & Pre & Post & Change \\
\hline & \multicolumn{8}{|c|}{ Dollar effective spread } \\
\hline 1 & 25 & 0.143 & 0.137 & -0.005 & 23 & 0.192 & 0.189 & -0.002 \\
\hline 2 & 25 & 0.135 & 0.131 & -0.004 & 23 & 0.197 & 0.193 & -0.004 \\
\hline 3 & 25 & 0.147 & 0.140 & -0.007 & 23 & 0.214 & 0.196 & -0.017 \\
\hline 4 & 25 & 0.156 & 0.160 & 0.004 & 23 & 0.243 & 0.216 & -0.027 \\
\hline 5 & 25 & 0.179 & 0.182 & 0.003 & 23 & 0.267 & 0.256 & -0.011 \\
\hline 6 & 25 & 0.193 & 0.229 & 0.036 & 23 & 0.328 & 0.290 & -0.038 \\
\hline 7 & 19 & 0.198 & 0.338 & 0.140 & 20 & 0.376 & 0.342 & -0.034 \\
\hline 8 & 23 & 0.262 & 0.489 & 0.227 & 22 & 0.425 & 0.446 & 0.021 \\
\hline 9 & 4 & 0.156 & 0.296 & 0.141 & 13 & 0.730 & 0.950 & 0.221 \\
\hline \multirow[t]{2}{*}{10} & NA & NA & NA & NA & 5 & 0.364 & 0.320 & -0.044 \\
\hline & \multicolumn{8}{|c|}{ Percentage effective spread } \\
\hline 1 & 25 & $0.15 \%$ & $0.13 \%$ & $-0.02 \%^{\mathrm{a}}$ & 23 & $0.21 \%$ & $0.22 \%$ & $0.02 \%$ \\
\hline 2 & 25 & $0.14 \%$ & $0.12 \%$ & $-0.02 \%^{\mathrm{a}}$ & 23 & $0.21 \%$ & $0.23 \%$ & $0.01 \%$ \\
\hline 3 & 25 & $0.15 \%$ & $0.13 \%$ & $-0.02 \%^{\mathrm{a}}$ & 23 & $0.23 \%$ & $0.23 \%$ & $0.00 \%$ \\
\hline 4 & 25 & $0.16 \%$ & $0.15 \%$ & $-0.01 \%$ & 23 & $0.26 \%$ & $0.26 \%$ & $-0.01 \%$ \\
\hline 5 & 25 & $0.18 \%$ & $0.17 \%$ & $-0.01 \%^{\mathbf{b}}$ & 23 & $0.29 \%$ & $0.31 \%$ & $0.01 \%$ \\
\hline 6 & 25 & $0.21 \%$ & $0.22 \%$ & $0.01 \%$ & 23 & $0.36 \%$ & $0.36 \%$ & $-0.01 \%$ \\
\hline 7 & 19 & $0.22 \%$ & $0.32 \%$ & $0.10 \%$ & 20 & $0.42 \%$ & $0.42 \%$ & $0.00 \%$ \\
\hline 8 & 23 & $0.28 \%$ & $0.43 \%$ & $0.15 \%$ & 22 & $0.46 \%$ & $0.53 \%$ & $0.07 \%$ \\
\hline 9 & 4 & $0.17 \%$ & $0.30 \%$ & $0.13 \%$ & 13 & $0.80 \%$ & $1.01 \%$ & $0.21 \%$ \\
\hline 10 & NA & NA & NA & NA & 5 & $0.36 \%$ & $0.37 \%$ & $0.01 \%$ \\
\hline
\end{tabular}

Table 6. Change in dollar and percentage effective spread Low-price \& High-volume stocks 1997 and 2001 NYSE tick size reductions.

\begin{tabular}{|c|c|c|c|c|c|c|c|c|}
\hline \multirow[b]{2}{*}{ Size } & \multicolumn{4}{|l|}{1997} & \multicolumn{4}{|l|}{2001} \\
\hline & Sample & Pre & Post & Change & Sample & Pre & Post & Change \\
\hline & \multicolumn{8}{|c|}{ Dollar effective spread } \\
\hline 1 & 34 & 0.117 & 0.072 & $-0.045^{\mathrm{a}}$ & 42 & 0.096 & 0.052 & $-0.044^{\mathrm{a}}$ \\
\hline 2 & 34 & 0.114 & 0.071 & $-0.043^{\mathrm{a}}$ & 42 & 0.099 & 0.056 & $-0.043^{\mathrm{a}}$ \\
\hline 3 & 34 & 0.111 & 0.070 & $-0.040^{\mathrm{a}}$ & 42 & 0.099 & 0.058 & $-0.04^{a}$ \\
\hline 4 & 34 & 0.108 & 0.070 & $-0.038^{\mathrm{a}}$ & 42 & 0.102 & 0.060 & $-0.042^{\mathrm{a}}$ \\
\hline 5 & 34 & 0.111 & 0.073 & $-0.038^{\mathrm{a}}$ & 42 & 0.110 & 0.068 & $-0.042^{\mathrm{a}}$ \\
\hline 6 & 31 & 0.115 & 0.077 & $-0.038^{\mathrm{a}}$ & 40 & 0.114 & 0.073 & $-0.042^{\mathrm{a}}$ \\
\hline 7 & 22 & 0.130 & 0.093 & $-0.037^{a}$ & 39 & 0.119 & 0.071 & $-0.048^{\mathrm{a}}$ \\
\hline 8 & 28 & 0.121 & 0.074 & $-0.047^{\mathrm{a}}$ & 38 & 0.125 & 0.072 & $-0.053^{\mathrm{a}}$ \\
\hline 9 & 10 & 0.083 & 0.074 & -0.010 & 22 & 0.142 & 0.081 & $-0.061^{b}$ \\
\hline \multirow[t]{2}{*}{10} & 4 & 0.101 & 0.068 & -0.033 & 15 & 0.137 & 0.108 & -0.030 \\
\hline & \multicolumn{8}{|c|}{ Percentage effective spread } \\
\hline 1 & 34 & $2.00 \%$ & $1.12 \%$ & $-0.88 \%{ }^{\mathbf{a}}$ & 42 & $2.18 \%$ & $1.02 \%$ & $-1.17 \%^{\mathrm{a}}$ \\
\hline 2 & 34 & $2.11 \%$ & $1.21 \%$ & $-0.91 \%{ }^{\mathbf{a}}$ & 42 & $2.35 \%$ & $1.15 \%$ & $-1.20 \%^{\mathrm{a}}$ \\
\hline 3 & 34 & $2.38 \%$ & $1.43 \%$ & $-0.95 \%{ }^{\mathbf{a}}$ & 42 & $2.51 \%$ & $1.30 \%$ & $-1.21 \%^{\mathrm{a}}$ \\
\hline 4 & 34 & $2.48 \%$ & $1.55 \%$ & $-0.93 \%^{\mathbf{a}}$ & 42 & $2.72 \%$ & $1.47 \%$ & $-1.26 \%{ }^{\mathrm{a}}$ \\
\hline 5 & 34 & $2.43 \%$ & $1.49 \%$ & $-0.94 \%{ }^{\mathbf{a}}$ & 42 & $2.83 \%$ & $1.58 \%$ & $-1.25 \%^{\mathrm{a}}$ \\
\hline 6 & 31 & $2.58 \%$ & $1.61 \%$ & $-0.97 \%{ }^{\mathbf{a}}$ & 40 & $3.10 \%$ & $1.81 \%$ & $-1.30 \%^{\mathrm{a}}$ \\
\hline 7 & 22 & $2.69 \%$ & $1.87 \%$ & $-0.82 \%^{\mathbf{a}}$ & 39 & $3.26 \%$ & $1.72 \%$ & $-1.54 \%^{\mathrm{a}}$ \\
\hline 8 & 28 & $3.21 \%$ & $2.01 \%$ & $-1.20 \%^{\mathrm{a}}$ & 38 & $3.25 \%$ & $1.90 \%$ & $-1.35 \%^{\mathrm{a}}$ \\
\hline 9 & 10 & $2.77 \%$ & $2.46 \%$ & $-0.31 \%$ & 22 & $3.88 \%$ & $2.40 \%$ & $-1.49 \%{ }^{\mathbf{b}}$ \\
\hline 10 & 4 & $11.03 \%$ & $2.36 \%$ & $-8.67 \%$ & 15 & $4.71 \%$ & $3.10 \%$ & $-1.61 \%$ \\
\hline
\end{tabular}

